\title{
Stable Isotope Dilution Analysis of Isovalerylglycine in Amniotic Fluid and Urine and Its Application for the Prenatal Diagnosis of Isovaleric Acidemia
}

\author{
DAVID G. HINE, ADELlE M. HACK, STEPHEN I. GOODMAN, AND KAY TANAKA \\ Yale University School of Medicine, Department of Human Genetics, New Haven, Connecticut 06510 [D. G. H., \\ A. M. H., K. T.l and University of Colorado, School of Medicine, Department of Pediatrics, \\ Denver, Colorado 80262 [S.I.G.]
}

\begin{abstract}
A stable isotope dilution method was developed to measure accurately small amounts of isovalerylglycine in amniotic fluid and urine for the prenatal diagnosis of isovaleric acidemia. $\left[4,4,4-D_{3}\right]$ Isovalerylglycine was synthesized and used as an internal standard. Samples were extracted, methylated, and analyzed by chemical ionization gas chromatography-mass spectrometry operated in the selected ion monitoring mode. This method is very sensitive (lower limit $\sim 5 \mathrm{ng} / \mathrm{ml}$ ), linear over three orders of magnitude above $10 \mathrm{ng} / \mathrm{ml}$ up to at least $10 \mu \mathrm{g} / \mathrm{ml}$ and reproducible. No isovalerylglycine was detected at all in amniotic fluids from eleven normal pregnant women with an exception of a single case which contained $6 \mathrm{ng} / \mathrm{ml}$. Amniotic fluids from five pregnancies at risk were analyzed. Two of these samples had isovalerylglycine concentrations of 957 and $556 \mathrm{ng} / \mathrm{ml}$. Three others contained 18, 18, and $17 \mathrm{ng} /$ $\mathrm{ml}$ of isovalerylglycine. Postpartum diagnostic tests and/or in vitro assay of isovaleryl-CoA dehydrogenase of $\left[1-{ }^{14} \mathrm{C}\right]$ isovaleric acid oxidation using amniocytes confirmed that the first two fetuses were affected by isovaleric acidemia, whereas the latter three were unaffected. The method described in this report provides a highly accurate and reliable technique for the prenatal diagnosis of isovaleric acidemia. (Pediatr Res 20: 222-226, 1986)
\end{abstract}

\section{Abbreviations}

CI, chemical ionization

$D_{3}$-IVG, $\left[4,4,4-D_{3}\right]$ isovalerylglycine

GC/MS, gas chromatography-mass spectroscopy

MLT, macromolecular labeling test

IVG, isovalerylglycine

SIM, selected ion monitoring

Isovaleric acidemia is an autosomal recessive inherited disorder of leucine metabolism due to a deficiency of isovaleryl-CoA dehydrogenase $(1,2)$. In patients with isovaleric acidemia, the majority of unoxidized isovaleryl-CoA is effectively conjugated with glycine by the action of glycine- $\mathrm{N}$-acylase, and continuously excreted as isovalerylglycine in large amounts of urine (3). This

Received June 10, 1985; accepted October 31, 1985

Address for Correspondence Kay Tanaka, M.D., Yale University School of Medicine, Department of Human Genetics, 333 Cedar Street, P. O. Box 3333, New Haven, CT 06510

Supported in part by NIH Grants AM29911 and AM12579 and March-ofDimes Grant I-378. detoxification mechanism is effective enough to prevent the accumulation of isovaleric acid in remission. However, during periods of acidosis, isovaleric acid accumulates in blood, and other secondary abnormal metabolites such as 3- and 4-hydroxyisovaleric acids (4-6), and isovaleryl glucuronide $(7,8)$ are also excreted in excess in urine. A few other minor metabolites including methylsuccinic (5), 3-hydroxyisoheptanoic (9), and isovalerylglutamic acids (10) have also been detected in small amounts in acidosis.

Although isovaleric acidemia was first reported in 1966 (1), its prenatal diagnosis has not been reported. To establish a practical, accurate method for the prenatal diagnosis of isovaleric acidemia, we developed a stable isotope dilution method for the analysis of isovalerylglycine in amniotic fluid. Since fetal urine is the main source of amniotic fluid, isovalerylglycine is expected to accumulate in the amniotic fluid of an affected fetus. It is not known, however, whether the glycine conjugation system is developed in the fetus at the time of amniocentesis. In rats and rabbits, glycine $\mathrm{N}$-acylase develops during the perinatal period (11). Even if this enzyme normally develops in the perinatal period in humans as well, we considered that the accumulation of isovaleryl-CoA in an affected fetus would induce the development of glycine- $\mathrm{N}$-acylase in early fetal life and ensure the excretion of isovalerylglycine by the fetus. We did not choose other metabolites since with the exception of isovaleryl glucuronide, they are excreted only during acidosis, and in much smaller amounts than IVG. Newborn babies with isovaleric acidemia are not acidotic immediately after birth (12). The stable isotope dilution method was employed since it provides the ultra-sensitivity necessary to accurately measure small amounts of IVG in normal amniotic fluids as well as those from affected pregnancies. It is fast, requiring only several hours (13). In our method presented here, we synthesized $D_{3}$-IVG, (Fig. 1) and used it as internal standard.

\section{MATERIALS AND METHODS}

Materials. $\left[4,4,4-\mathrm{D}_{3}\right]$ isovaleryl chloride $\left(99 \% \mathrm{D}_{3}\right.$ at one of the methyls at C-4) was custom synthesized by Merck, Sharp and Dohm (Point Clair, Quebec, Canada). Glycine (electrophoresis purity) was purchased from BioRad (Richmond, CA). Ethyl acetate (Gold label) was obtained from Aldrich Chemical Co. (Milwaukee, WI). Gaseous diazomethane was generated in small amounts as needed from N-nitrosomethylurea (K\&K Rate and Fine Chemicals, Plainview, NY), according to the method previously described (14). SE-30 was purchased from Analabs (North Haven, CT).

Synthesis of $D_{3}-I V G . \mathrm{D}_{3}$-IVG was synthesized from $\left[4,4,4-\mathrm{D}_{3}\right]$ 
(A) $\mathrm{Mr}=173$<smiles>COC(=O)CNC(=O)CC(C)C</smiles>

(B) $\mathrm{Mr}=176$<smiles>COC(=O)CNC(=O)CC(C)C</smiles>

Fig. 1. Chemical structures of the natural IVG $(A)$ and $\mathrm{D}_{3}-\mathrm{IVG}(B)$

-isovaleryl chloride $(2.4 \mathrm{~g})$ and glycine $(1.4 \mathrm{~g})$ according to the method previously described (3). The product was recrystallized twice from ethyl acetate/hexane $(1: 3) ; 1.6 \mathrm{~g}$ of $\mathrm{D}_{3}$-IVG were obtained. The chemical purity and isotopic enrichment were 99 and $98.91 \%$, respectively, as determined by GC/MS.

Preparation of patient samples for analysis. Amniotic fluid samples were obtained by amniocentesis at 15-24 wk gestation and were stored, after the cells were separated by centrifugation, at $-20^{\circ} \mathrm{C}$ until analysis. $\mathrm{D}_{3}$-IVG was added to the amniotic fluid supernatant $(1.0-3.0 \mathrm{ml})$ so that the final concentration was 1 $\mu \mathrm{g} / \mathrm{ml}$. The sample was largely deproteinized by acidification to pH 1.0 with $6 \mathrm{~N} \mathrm{HCl}$ and saturation with an excess of sodium chloride. The sample was centrifuged for $10 \mathrm{~min}$ and the clear supernatant was transferred to another tube. The sample was resaturated with sodium chloride and extracted four times with equal aliquots of ethyl acetate. The combined extracts were dried over anhydrous sodium sulfate, filtered, and evaporated just to dryness under a stream of nitrogen in a $60^{\circ} \mathrm{C}$ water bath. The residue was immediately redissolved in $0.1 \mathrm{ml}$ of methanol and $0.5 \mathrm{ml}$ of diethyl ether. The sample was methylated by bubbling gaseous diazomethane through the solution as described previously (14). The volume was reduced to approximately $50 \mu \mathrm{l}$ with a gentle stream of nitrogen at room temperature. The sample was stored in a tightly sealed vial until analysis. Samples were stable for several weeks.

Maternal urine samples, obtained at $15-37$ wk gestation period, were prepared in the similar manner, omitting the deproteinization step. One $\mathrm{ml}$ of urine was taken for analysis and creatinine concentrations were determined colorimetrically according to the method of Taussky (15). IVG concentrations were reported in the convenient units of $\mathrm{ng} / \mathrm{ml}$ for amniotic fluids and in $\mu \mathrm{g} / \mathrm{mg}$ creatinine for urine samples.

$G C / M S$. A Finnigan $4510 \mathrm{GC} / \mathrm{MS}$ with a Nova computer was used in the chemical ionization $(\mathrm{CI})$, selected ion monitoring (SIM) mode. One to $3 \mu \mathrm{l}$ of methylated sample was injected onto a $1.8 \mathrm{~m} \times 2 \mathrm{~mm}$ glass column packed with $5 \%$ SE-30 on $80 / 90$ mesh Anakrom K (Analabs, North Haven, CT), with a helium flow rate of $25 \mathrm{ml} / \mathrm{min}$. The injection port, separator, transfer line, and ion source temperature were kept at 225, 250, 280, and $100^{\circ} \mathrm{C}$, respectively. Methane was used as the reagent gas at a source pressure of 0.25 torr. The ionizing voltage was $50 \mathrm{eV}$. The column was programmed from 70 to $150^{\circ} \mathrm{C}$ at $6^{\circ} \mathrm{C} / \mathrm{min}$ after an initial isothermal delay of $1 \mathrm{~min}$. The solvent peak was diverted for $2 \mathrm{~min}$ at the start of the run. CI spectra were obtained by scanning from $\mathrm{m} / \mathrm{z} 100$ to $\mathrm{m} / \mathrm{z} 400$ at a rate of $2.4 \mathrm{~s} /$ cycle. In the SIM mode, the protonated molecular ions $\left(\mathrm{MH}^{+}\right)$at $\mathrm{m} / \mathrm{z}$ 174 and $\mathrm{m} / \mathrm{z} 177$, for IVG and $D_{3}-\mathrm{IVG}$, respectively, were repetitively scanned with a $100 \mathrm{~ms}$ dwell time. Peak areas were calculated by the computer.

A standard curve was generated for the ratio of peak area at $\mathrm{m} / \mathrm{z} 174$ and that at $\mathrm{m} / \mathrm{z} 177$ versus the ratio of the amounts of IVG/D 3 -IVG. All such standard samples contained $1 \mu \mathrm{g} / \mathrm{ml}$ of $\mathrm{D}_{3}$-IVG and variable amounts of IVG ranging from 0.001 to $10.000 \mu \mathrm{g} / \mathrm{ml}$, and were carried through the same work-up procedure as the amniotic fluid samples. The synthetic $\mathrm{D}_{3}-\mathrm{IVG}$ contained a small amount $(1.09 \%)$ of natural IVG. This percentage was determined very accurately, and the observed peak area ratios in the sample were adjusted accordingly. The equation of the line was obtained by linear regression analysis and the amount of IVG in patient samples was calculated from the equation. Standard samples were periodically reanalyzed to verify the validity of the equation.

\section{RESULTS}

$C I$ mass spectra of $I V G$ and $D_{3}-I V G$. Chemical structures of IVG and $D_{3}$-IVG are shown in Figure 1 . The molecular weight of the natural IVG as the methyl ester is 173 , while that of $D_{3}$ IVG is 176 due to three deuterium atoms at the C-4 position of its isovaleryl moiety. The CI mass spectra of IVG and $D_{3}-I V G$ are shown in Figure 2. Unlike in electron impact mass spectra (3), a relatively small number of large fragments are observed. In each case, the protonated molecular ion $\left(\mathrm{MH}^{+}\right)$is the base peak: these are the peaks at m/z 174 and 177 for IVG and $D_{3^{-}}$ IVG, respectively. There are several other much smaller but significant peaks. Peaks at m/z 142 and 145 are due to loss of a methoxy from the carboxymethyl group of each compound. The peaks at $\mathrm{m} / \mathrm{z} 202$ and 214 in the natural IVG and those at $\mathrm{m} / \mathrm{z}$ 205 and 217 in $\mathrm{D}_{3}$-IVG represent $\left(\mathrm{M}+29^{+}\right)$and $\left(\mathrm{M}+41^{+}\right)$ions, respectively. These ions are due to adducts of the parent molecule and hydrocarbons $\left(\mathrm{C}_{2} \mathrm{H}_{5}{ }^{+}\right.$or $\left.\mathrm{C}_{3} \mathrm{H}_{5}{ }^{+}\right) \cdot\left(\mathrm{M}+29^{+}\right)$and $\left(\mathrm{M}+41^{+}\right)$

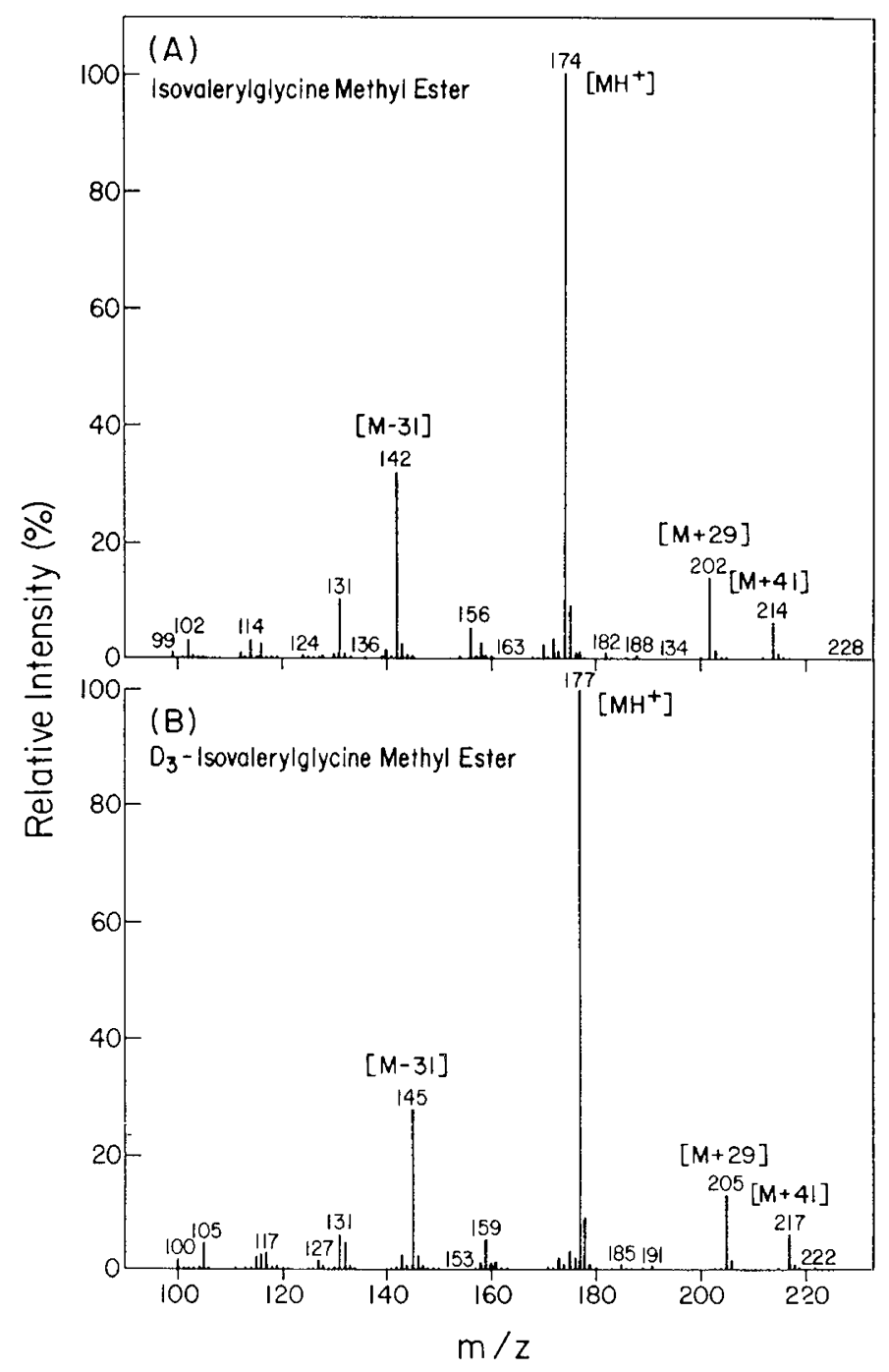

Fig. 2. CI mass spectrum of the methyl ester of IVG $(A)$ and CI mass spectrum of the methyl ester of $\mathrm{D}_{3}-\mathrm{IVG}(B)$. 
ions are commonly observed in CI mass spectra using methane gas as reactant gas (13).

Selected ion monitoring and construction of standard curve. The protonated molecular ions at m/z 174 and 177 were monitored using GC/MS in the SIM mode to quantitate the natural and $\mathrm{D}_{3}-\mathrm{IVG}$, respectively. The high intensity of these ions provided excellent sensitivity. A standard curve was constructed as follows. Standard solutions which contained a fixed amount of $\mathrm{D}_{3}-\mathrm{IVG}(1 \mu \mathrm{g} / \mathrm{ml})$ and a variable amount of IVG $(0.001-10 \mu \mathrm{g} /$ $\mathrm{ml})$ were prepared and carried through the procedure of extraction, derivatization, and GC/MS analysis. The ratio of the peak area of the protonated molecular ion of IVG to that of $D_{3}-\mathrm{IVG}$ was determined. Excellent linearity over a range of three orders of magnitude was obtained above $10 \mathrm{ng} / \mathrm{ml}$. The correlation factor was 0.9999 . The slope was 0.92 , slightly less than theoretical but was consistently observed. Also, the points of $50 \mathrm{ng} / \mathrm{ml}$ and below slightly shifted upward (slope 1.09). The shift was

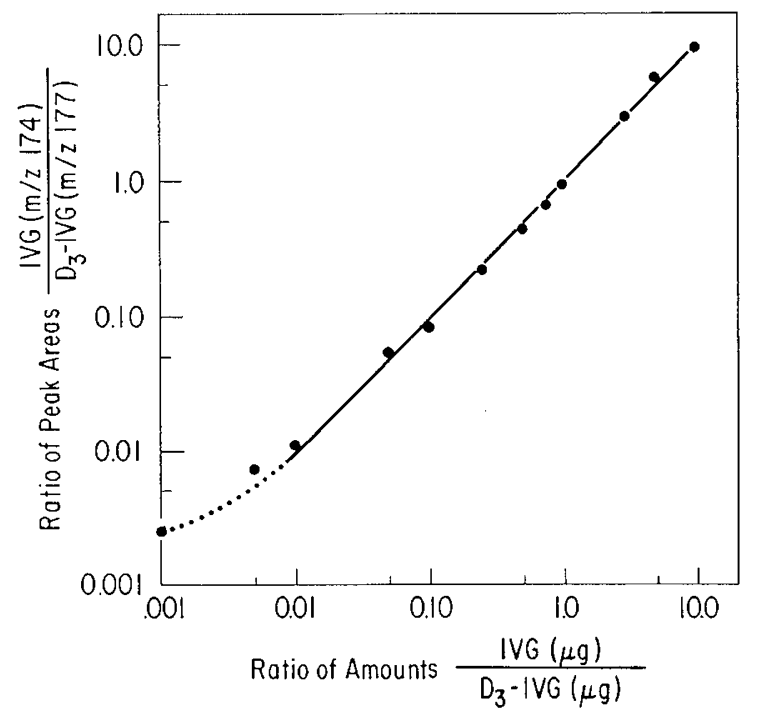

Fig. 3. Calibration curve for various ratios of IVG and $D_{3}-I V G$ versus the observed peak ratios of $\mathrm{m} / \mathrm{z} 174 \mathrm{~m} / \mathrm{z} 177$. Details are described in the text.

Table 1. Recovery of IVG from amniotic fluid

\begin{tabular}{cccc}
\hline $\begin{array}{c}\text { Amount added } \\
(\mathrm{ng} / \mathrm{ml})\end{array}$ & $\begin{array}{c}\text { Amount detected } \\
(\mathrm{ng} / \mathrm{ml})\end{array}$ & $\begin{array}{c}\text { Recovery } \\
(\%)\end{array}$ & $\begin{array}{c}\text { No. of } \\
\text { experiments }\end{array}$ \\
\hline 0 & 0 & & 3 \\
100 & $100 \pm 3^{*}$ & 100 & 3 \\
\hline
\end{tabular}

* Mean $\pm 1 \mathrm{SD}$. more prominent at $5 \mathrm{ng} / \mathrm{ml}$. The line intercepted $Y$ axis at 0.0048 . The calibration curve is presented in log-log scale in Figure 3 , in order to cover a wide range. Five $\mathrm{ng} / \mathrm{ml}$ IVG could be detected. This result indicates that samples with an IVG concentration above $10 \mathrm{ng} / \mathrm{ml}$ up to at least $10 \mu \mathrm{g} / \mathrm{ml}$ can be accurately determined.

Recovery and precision of the assay. The recovery and precision of the analysis was determined using a pooled amniotic fluid. Six 3-ml aliquots were used for this experiment. Three of them were fortified with $100 \mathrm{ng} / \mathrm{ml}$ of the natural IVG. The samples were analyzed as described above and the results are presented in Table 1. Quantitative recovery with excellent precision was obtained.

Determination of isovalerylglycine concentration in amniotic fluid from normal and at-risk pregnancies. IVG concentrations in normal amniotic fluids and those from at risk pregnancies are listed in Table 2. All amniotic fluids were obtained at 16-24 wk of gestation. The results of $\left[1-{ }^{14} \mathrm{C}\right]$ isovaleric acid MLT assay on amniocytes, which measures the ability of cells to oxidize $\left[1-{ }^{14} \mathrm{C}\right]$ isovaleric acid (16), and those of postnatal studies are also listed. The amount of IVG in normal amniotic fluid is extremely low.

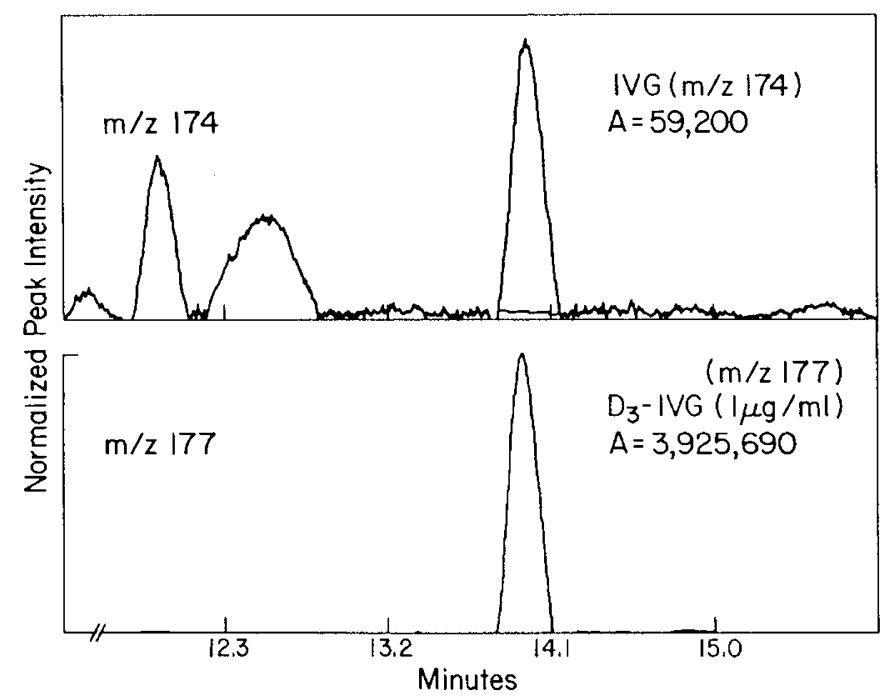

Fig. 4. Selected ion monitor chromatograms of a normal amniotic fluid. Three $\mathrm{ml}$ of the amniotic fluid was used for the analysis. Peak areas are shown in the right hand side of the chromatograms. The height of the highest peak is normalized to $100 \%$ ( $\mathrm{Y}$ axis) by a computer program regardless of the actual amount. The amount of the natural or $\mathrm{D}_{3}$-IVG is represented by the peak area number $(A)$ printed out by the computer. The peak area for $\mathrm{m} / \mathrm{z} 177$ corresponds to $1 \mu \mathrm{g} / \mathrm{mI}$ of the internal standard $\mathrm{D}_{3}$-IVG.

Table 2. IVG concentrations in amniotic fluid and MLT activity in amniocytes from pregnant women at-risk

\begin{tabular}{cccc}
\hline Cell lines & $\begin{array}{c}\text { Isovalerylglycine in } \\
\text { amniotic fluid } \\
(\mathrm{ng} / \mathrm{ml})\end{array}$ & $\begin{array}{c}\text { MLT activity } \\
\text { in amniocytes } \\
\text { (nmol/mg protein/day) }\end{array}$ & $\begin{array}{c}\text { Postnatal } \\
\text { study }\end{array}$ \\
\hline Control & $\begin{array}{c}0^{*} \\
(11) \dagger\end{array}$ & $14.8 \pm 5.9$ \\
At risk pregnancy & 18 & 9.0 & Not affected \\
Case 1 & 957 & Deficient & Affected \\
Case 2 & 556 & 0.97 & Affected \\
Case 3 & 17 & 10.0 & Not affected \\
Case 4 & 18 & 6.8 & Not affected \\
Case 5 & & & \\
\hline
\end{tabular}

* Ten of eleven normal amniotic fluids contained no detectable amount of isovalerylglycine at all. One contained $6 \mathrm{ng} / \mathrm{ml}$.

$\dagger$ The numbers in parentheses indicate the number of cases tested.

$\ddagger$ Isovaleryl-CoA dehydrogenase activity in this cell line was approximately $20 \%$ of that in normal fibroblasts. Amniocytes were not available for MLT (details are in text). 


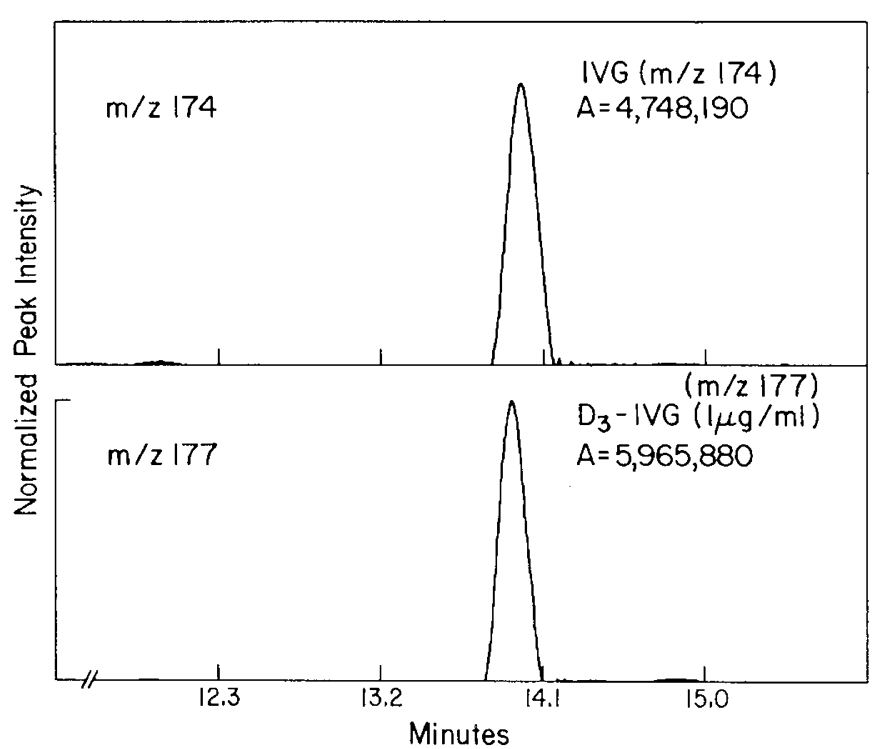

Fig. 5. Selected ion monitor chromatograms of the amniotic fluid from a pregnancy carrying a fetus affected by isovaleric acidemia (case 2). Three $\mathrm{ml}$ of the amniotic fluid was used for the analysis. Peak areas are shown in the right hand side of the chromatograms. The height of the highest peak is normalized to $100 \%$ ( $\mathrm{Y}$ axis) by a computer program regardless of the actual amount. The amount of the natural or $\mathrm{D}_{3}-\mathrm{IVG}$ is represented by the peak area number $(A)$ printed out by the computer. The peak area for $\mathrm{m} / \mathrm{z} 177$ corresponds to $1 \mu \mathrm{g} / \mathrm{ml}$ of the internal standard $\mathrm{D}_{3}$-IVG.

Ten of 11 normal amniotic fluids contained no measurable IVG, and the other contained only $6 \mathrm{ng} / \mathrm{ml} \mathrm{IVG}$. In contrast, amniotic fluids from cases 2 and 3 contained huge amounts, 957 and 556 $\mathrm{ng} / \mathrm{ml}$, respectively, of IVG. SIM chromatogram of a normal and that of an affected case (case 2) are shown in Figures 4 and 5 , respectively. MLT activity in amniocytes from case 3 was only $6.5 \%$ of the mean of the activity from control amniocytes. Amniocytes from case 2 were not available for MLT assay, but isovaleryl-CoA dehydrogenase activity was approximately $20 \%$ of the mean of the activity from control fibroblasts (17). IVG concentrations in amniotic fluids from three other at-risk pregnancies (cases 1, 4, and 5) were much smaller, ranging 17-18 $\mathrm{ng} / \mathrm{ml}$. MLT activities in cases 1,4 , and 5 ranged from low normal to approximately $50 \%$ of mean of controls. Thus, the results of amniotic fluid IVG concentration, determined by the present method, were concordant with those of MLT or isovaleryl-CoA dehydrogenase assay, indicating that cases 2 and 3 were each carrying an affected fetus whereas those of cases 1,4 , and 5 were not affected. These results were later confirmed by postnatal studies in all cases.

Determination of urinary isovalerylglycine excretion. The mean of the isovalerylglycine concentrations in urines from three normal pregnant women at $16-24 \mathrm{wk}$ was $1.7 \pm 0.7 \mu \mathrm{g} / \mathrm{mg}$ creatinine. We measured IVG in urines from two at-risk pregnancies, each carrying an unaffected fetus. Urines were collected during the 14-16th wk of pregnancy in one case (case 6) and in the last 3 months of pregnancy in the other (case 7). That cases 6 and 7 were unaffected was confirmed by postnatal studies. The mean of the three urines from case 6 was $1.7 \pm 0.3 \mu \mathrm{g} / \mathrm{mg}$ creatinine. Six urines from case 7 collected in the 16-30th wk of pregnancy ranged from 5.7 to 9.3 with a single high value of 15.1 $\mu \mathrm{g} / \mathrm{mg}$ of creatinine (21 st wk). We also analyzed urines from two at-risk pregnancies carrying an affected fetus. The IVG concentration from case 2 at the 16 th wk of gestation was $17.5 \mu \mathrm{g} / \mathrm{mg}$ creatinine. Three urines collected from case 3 in the $35-37$ th wk of pregnancy were $23.2,37.1$, and $43.7 \mu \mathrm{g} / \mathrm{mg}$ creatinine in the chronological order.

\section{DISCUSSION}

Prenatal diagnostic methods, based either on the metabolite determination in amniotic fluid or on in vitro assays using amniocytes, have been reported for a number of metabolic disorders (18). This report describes the first successful prenatal diagnosis of isovaleric acidemia. This was accomplished mainly using the stable isotope dilution analysis of isovalerylglycine. We also utilized the in vitro assays using amniocytes to verify the accuracy of the diagnosis established using the stable isotope dilution analysis.

Metabolite analysis in amniotic fluid, mainly using GC or GC/ MS alone had been reported in occasional cases for numerous disorders. However, the reliability of GC or GC/MS analysis in general use for prenatal diagnosis has not been convincingly established for many disorders. Accurate quantitation of metabolites in normal amniotic fluid by $\mathrm{GC}$ or $\mathrm{GC} / \mathrm{MS}$ alone is difficult due to the extremely small amount of metabolites. Even the increased amounts of metabolites accumulating in amniotic fluids in affected pregnancies are very small from the standpoint of ordinary analytical chemistry. The GC or GS/MS analysis of a minute amount of compound is not quantitative nor reproducible below certain levels due to adsorption to the internal surfaces of glassware, chromatographic columns, and connecting tubings used in the procedure. For example, isovalerylglycine could not be detected at all in the amniotic fluid from case 2 by a regular GC/MS-SIM method without the labeled standard. For these reasons, a more reliable method of analysis was desirable for the purpose of prenatal diagnosis. Until recently, in vitro assays using amniocytes were regarded more reliable. However, the application of stable isotope dilution analysis for the determination of metabolites in amniotic fluid has overcome the shortcomings. An analog labeled with stable isotope, as analyzed using GC/MS in the SIM mode, serves as a carrier as well as an internal standard, preventing and circumventing the inaccuracy due to the loss of the compound being analyzed. This method provides extremely high sensitivity and excellent precision and reproducibility in the very low range which could not be achieved by $\mathrm{GC}$ or GC/MS alone. In addition, this method is fast, taking only several hours as shown here and elsewhere (13). This is in contrast to the in vitro assay using amniocytes which requires several weeks to obtain a sufficient amount of cells by culture for the assay. The stable isotope dilution method has now been applied to the prenatal diagnosis of several inborn metabolic disorders, including methylmalonic acidemia $(13,19,20)$, propionic acidemia (21), and galactosemia (22), and its accuracy has been confirmed.

We have shown here that the isotope dilution analysis of IVG in amniotic fluid using $D_{3}$ IVG was highly sensitive and extremely accurate. As determined by this method, ten of eleven normal amniotic fluids did not contain any detectable amount of IVG. One of them contained $6 \mathrm{ng} / \mathrm{ml}$ of IVG. In contrast, amniotic fluids from three at-risk pregnancies, each carrying an unaffected fetus, consistently contained a small amount $(17-18 \mathrm{ng} / \mathrm{ml})$ of IVG, segregating them from normal controls. However, further study is necessary to determine whether this difference between unaffected at-risk pregnancies and normal pregnancies is reproducible or not. The amniotic fluids from two at-risk pregnancies, each carrying an affected fetus, contained a huge amount of IVG, which was 30-60 times greater than the level found in the unaffected cases. Thus, the two groups of at-risk pregnancies were clearly segregated and there was no ambiguity in the diagnosis. The diagnoses made by this method were later confirmed, with perfect concordance in all five cases by in vitro studies and by postnatal investigation.

In regard to the absence of IVG in normal amniotic fluid, it is interesting to note that in rats and rabbits, glycine $\mathrm{N}$-acylase, which is responsible for the biosynthesis of IVG, is absent in the early stage of fetal life, and it develops only in the perinatal period. The developmental aspects of this enzyme in humans 
has not been studied. It is not known whether it is present or absent in a normal human fetus. However, the large amounts of IVG detected in the amniotic fluids from the two affected pregnancies clearly indicate that glycine $\mathrm{N}$-acylase is present in these fetuses. If this enzyme is absent in normal human fetuses, then we have to assume that glycine $\mathrm{N}$-acylase was induced by high concentrations of isovaleryl-CoA in the affected fetuses.

The urinary IVG concentrations in an affected pregnancy (case 1) measured at the 16 th wk of gestation was ten times the normal level. The IVG concentrations from the other affected pregnancy (case 2) were increasingly elevated 15-25 times normal towards the end of pregnancy. Thus, it appears that pregnant women carrying affected fetuses excrete increased amounts of IVG. However, increased urinary excretion of IVG in a range of three to nine times normal was also observed in an at-risk pregnancy with an unaffected fetus at the 16 to 30 th wk of pregnancy, while perfectly normal values were observed in the other. Therefore, the analysis of IVG in amniotic fluid is a more accurate diagnostic method than the analysis of urinary IVG.

Our technical experience in devising the present method warrants some comments. Although stable isotope dilution analysis provides high sensitivity and precision in general, the labeled internal standard must be carefully selected. Internal standards with labile labels must be avoided. In general, in compounds with a carboxyl group(s), deuterium at the $\alpha$-position is labile, and compounds with deuterium at the $\alpha$-positions are not adequate as an internal standard. In the early stages of the present study, we synthesized isovaleryl[2,2- $\left.\mathrm{D}_{2}\right]$ glycine as an internal standard. However, these deuterium atoms were partially exchanged with hydrogens in the media in the synthesis as well as during the extraction/derivatization procedure in its use as an internal standard. The labels in this compound were labile because they were located at the $\alpha$-position in the glycine moiety. As a result, the sensitivity and precision were relatively low when isovaleryl $\left[2,2-\mathrm{D}_{2}\right]$ glycine was used an an internal standard. In contrast, the labels in $D_{3}$-IVG, utilized in the present study, were stable and thus provided the extremely high sensitivity and excellent precision.

Acknowledgments. The authors thank Drs. Ira Brand, Jess Thoene, Sechin Cho, T. Kurecynski, John Harper, and Ann Marie Sommer for providing amniotic fluids and urines.

\section{REFERENCES}

1. Tanaka K, Budd MA, Efron ML, Isselbacher KJ 1966 Isovaleric acidemia: a new genetic defect of leucine metabolism. Proc Natl Acad Sci USA 56:236242

2. Rhead WJ, Tanaka K 1980 Demonstration of a specific isovaleryl-CoA dehydrogenase deficiency in fibroblasts from patients with isovaleric acidemia. Proc Natl Acad Sci USA 77:580 -583
3. Tanaka K, Isselbacher KJ 1967 The isolation and identification of $\mathrm{N}$-isovalerylglycine from urine of patients with isovaleric acidemia. J Biol Chem 242:2966-2972

4. Tanaka K, Orr JC, Isselbacher KJ 1968 Identification of $\beta$-hydroxyisovaleric acid in the urine of a patient with isovaleric acidemia. Biochim Biophys Acta 152:638-641

5. Truscott RJW, Malegan D, McCairns E, Burke D, Hick L, Sims P, Halpern B, Tanaka K, Sweetman L, Nyhan WL, Hammond J, Bumack C, Haan EA, Danks DM 1981 New metabolites in isovaleric acidemia. Clin Chim Acta 10:187-203

6. Lehnert W, Niederhoff $\mathrm{H} 1981$ 4-Hydroxyisovaleric acid: a new metabolite in isovaleric acidemia. Eur J Pediatr 136:281-283

7. Hine DG, Tanaka K 1984 The identification and excretion pattern of isovaleryl glucuronide in the urine of patients with isovaleric acidemia. Pediatr Res 18:508-512

8. Dorland L, Duran M, Wadman SK, Niederwieser A, Bruinvis L, Ketting D 1983 Isovalerylglucuronide, a new urinary metabolite in isovaleric acidemia. Identification problems due to rearrangement reactions. Clin Chim Acta 134:77-83.

9. Lehnert W 1981 3-Hydroxyisoheptanoic acid: A new metabolite in isovaleric acidemia. Clin Chim Acta 113:101-103

10. Lehnert W 1981 Excretion of $\mathrm{N}$-isovalerylglutamic acid in isovaleric acidemia. Clin Chim Acta 116:249-252

11. James MO, Bend JR 1978 Perinatal development of, and effect of chemical treatment on glycine $\mathrm{N}$-acyltransferase activities in liver and kidney of rabbit and rat. Biochem J 172:293-299

12. Tanaka K, Rosenberg LE 1982 Disorders of branched chain amino acid and organic acid metabolism. In: Stanbury JB, Wyngaarden JB, Fredrickson DS, Goldstein JZ, Brown MS, The Metabolic Basis of Inherited Disease (eds) 5th ed. McGraw-Hill, New York pp 440-473

13. Zinn AB, Hine DG, Mahoney MS, Tanaka K 1982 The stable isotope dilution method for measurement of methylmalonic acid: a highly acurate approach to the prenatal diagnosis of methylmalonic acidemia. Pediatr Res 16:740745

14. Ramsdell HS, Tanaka K 1977 Gas chromatographic studies of twenty acylglycines of clinical importance. Clin Chim Acta 74:109-114

15. Taussky H 1954 A microcolorimetric determination of creatinine in urine by the Jaffe reaction. J Biol Chem 208:853-861

16. Dubiel B, Dabrowski C, Wetts R, Tanaka K 1983 Complementation studies of isovaleric acidemia and glutaric aciduria type Il using cultured skin fibroblasts. $\mathrm{J}$ Clin Invest 72:1543-1552

17. Frerman FE, Goodman SI 1985 Fluorometric assay of acyl-CoA dehydrogenases in normal and mutant human fibroblasts. Biochem Med 33:38-44

18. Patrick AD 1984 Prenatal diagnosis of inherited metabolic diseases. In: Roderick $\mathrm{CH}$, Nicolaides $\mathrm{KH}$ (eds). Prenatal Diagnosis. Royal College of Obstetrics and Gynecology, pp 121-132

19. Trefz FK, Schmidt H, Tauscher B, Depene E, Baumgartner R, Hammersen $G$, Kochen W 1981 Improved prenatal diagnosis of methylmalonic acidemia: mass fragmentography of methylmalonic acid in amniotic fluid and maternal urine. Eur J Pediatr 137:261-266

20. Sweetman L, Naylor G, Ladner T, Holm J, Nyhan WL, Hornbeck C, Griffiths J, Morbach L, Brandange S, Gruenke L, Craig JC 1982 Prenatal diagnosis of propionic and methylmalonic acidemia by stable isotope dilution analysis of methylcitric and methylmalonic acids in amniotic fluids. In: Schmidt HL, Forstel H, Heizinger K (eds) Stable Isotopes. Elsevier Sci Publ Co, Amsterdam, pp 287-293

21. Naylor G, Sweetman L, Nyhan WL, Hornbeck C, Griffiths J, Morch L, Brandange $S 1980$ Isotope dilution analysis of methylcitric acid in amniotic fluid for the prenatal diagnosis of propinonic and methylmalonic acidemia. Clin Chim Acta 107:175-183

22. Jakobs C, Warner TG, Sweetman L, Nyhan WL 1984 Stable isotope dilution analysis of galactitol in amniotic fluid: an accurate approach to the prenatal diagnosis of galactosemia. Pediatr Res 18:714-718 